\title{
A Study on the Landscape Plant Culture and Utilization Strategy in Heilongjiang Major Minority Areas
}

\author{
Fengli $\mathrm{Yu}^{1, \mathrm{a}}$ \\ ${ }^{1}$ Heihe University, Heihe, Heilongjiang, 164399, China \\ ${ }^{\mathrm{a}}$ email,
}

Keywords: Landscape Plant Culture, Utilization Strategy, Heilongjiang Major Minority Areas

\begin{abstract}
Based on the analysis of the relationship between garden, plant and culture and the origin of plant culture of major ethnic minorities in Heilongjiang Province, this paper makes a preliminary study on the application of plants to several major ethnic minorities in ideology. And then we elaborated the practical significance of research and development of minority garden plants and culture in landscape design, tourism resources development, ecological environment protection and biodiversity conservation.
\end{abstract}

\section{Introduction}

Since ancient times, gardens, plants and culture have inextricably linked, with profound cultural connotation, profound artistic layout and plant disposition is one of the famous garden features in our country. Chinese vast territory, many ethnic groups, rich in plant resources, different ethnic groups have given different cultural connotations of plants, with different characteristics of garden plants, constitute a different ethnic characteristics of the garden.

Heilongjiang is located in the northeast of the motherland is the national minority ethnic groups and ethnic minorities more provinces. Heilongjiang ethnic minority generations of life, multiply in this unique natural environment, and local plants are closely linked, not only the use of plants for its survival and life services, but also artificially to give plants from many human cultural activities of their own cultural connotation, so that plants become a cultural carrier, the so-called cultural plants.

Culture, in a broad sense, refers to the human society and historical practice in the process of creating the sum of material wealth and spiritual wealth in the narrow sense, refers to the social ideology and the corresponding system and organization. Culture is national, there are a number of cultural categories are born in a certain environment, different ethnic groups have different cultural background, and thus produce different types of culture. Heilongjiang ethnic minority plant culture is the people of all ethnic groups in the long-term social practice the combination of material wealth and spiritual wealth, which is based on the plant and the background of the ethnic minority culture, is a kind of unique cultural type. This paper aims at several major ethnic minorities in Heilongjiang province. The garden and the cultural connotation of the plant and its cultural connotation of the investigation and research for the characteristics of ethnic minority garden, ethnic garden plant allocation to provide the basis for the cultural category involved only ideology, only to discuss the spiritual and cultural fields involved in the plant.

\section{The Main Ethnic Minority Areas in Heilongjiang Province}

Heilongjiang Province, a total of 10 ethnic minority ethnic groups, they live in the region rich in natural resources, vast, but uneven spatial distribution, and facing the withdrawal. The survey shows that there are more than 90 various types of nature reserves at all levels in the settlements of ethnic minorities in our province, accounting for nearly 50\% of the province's nature reserves.

According to the World Wide Fund for Nature statistics, nearly 20\% of the earth's surface area and $85 \%$ of the protected areas are occupied by indigenous people. Half of the indigenous people live in tropical rainforests, while $80 \%$ of the earth's biodiversity is located in tropical rainforests. This fact shows that cultural diversity and biodiversity are closely related and indivisible. There are about 10,000 inhabitants in the protected area on a global scale, showing a wide distribution. 
Heilongjiang Province, the establishment of ethnic minority areas at all levels of various types of nature reserves to rescue and maintain the ecological environment. They have played an important role in protecting natural resources such as ecosystems, wildlife resources and natural relics, and have received good ecological benefits, social benefits and economic benefits. However, these protected areas are mainly based on the classification of resources, such as wetland type protected areas, protected areas of wild flora and fauna, forest ecosystems, while ignoring the integrity and system of natural resources as an integral part of the ecosystem, resulting in the cross between the protected areas contained in the chaotic situation. Because in practice, there is almost no single natural resource protected area, although it may be in some areas a particular type of resource is particularly prominent; but in many cases, different resources of the region is overlapping with each other. And the departments involved in the management of the province's nature reserves have one of the reasons that forestry departments, environmental protection departments, water conservancy departments, agricultural departments, geology and mineral resources departments, other departments and management departments cannot form effective management.

At present, the ethnic minorities in Heilongjiang Province are faced with unprecedented natural resources and ecological environment crisis and the nature reserves around the settlements are faced with many contradictions such as economic development, social stability, cultural inheritance and environmental protection. The reasons are complex and there are natural reasons, historical reasons and the reality of human activities. In particular, these environmental problems have caused the fragile ecological environment of ethnic minorities to be further damaged, leading to the shaking of the social and economic base of ethnic minorities and the survival crisis in the wider areas of national culture, national psychology and national society.

Therefore, the contradiction between the national survival, development and natural resources protection in the nature reserve located in the ethnic minority areas is more serious. On the issue of community co-management, the special culture and emotion of the ethnic minorities should be considered, and the nature protection of the Han nationality district in the management of a certain degree of particularity. The nature reserves in the region are faced with unique contradictions in the construction and management of unique protected areas and community development. Natural resources exist in a certain area, community residents are also living in the same area, the two are often relying on each other, the establishment of protected areas, the emergence of natural resources protection and community development is not coordinated, specifically for the resources and population, environment and development, protection and utilization, ownership disputes and many other issues.

\section{The Major Minority Garden Plants Classification in Heilongjiang Province}

The plants used by major ethnic minorities in Heilongjiang cover all aspects of social life. According to the survey, garden plants that are closely related to life and culture can be summarized as follows.

Divine Plants. For many modern people, the origin of life may have been a long time, but the real life of the sick and die, the well-being is necessary to face the ancestors handed down the tree, God is the master of its own, so the ethnic groups often selected a tree or a tree as a tree or god to protect the tree, carefully worship .This kind of god tree or tree used as the Walled God tree, Walled tree, mountain tree, dragon tree, etc., that the gods can bless the village safe and sound, People and animals thriving. Walled village is the soul of the village.

Plant Language and Plant Letter. Heilongjiang ethnic minorities in the long-term production practice and social life, and the plant had a close contact, understanding, familiar with the characteristics and habits of plants, different plants had a sense of malice, so that their favorite plants and some beautiful Things, good wishes to link up, over time, in a nation or a region of the plant has a specific language, can express people's thoughts and feelings, and thus can pass special information. 


\section{The Major Minority Garden Plants Features in Heilongjiang Province}

Plant is the composition of the garden elements can reflect the landscape characteristics of the garden, in the study of Heilongjiang ethnic minority garden characteristics, the characteristics of plant research is particularly important. Through the survey of the garden plants and cultural connotation of the study, I think the main ethnic minorities in Heilongjiang application of the garden plants have the following four characteristics.

Plants Are Closely Related to the Cultural Background. Multiple ethnic villages in the village outside the application of plants, mostly closely related with the cultural background, these divine plants, religious plants, and other elements of the garden, such as national architecture, decorative sketches and other side by side, the formation of attractions, together constitute a national landscape with the characteristics.

The Distinctive Regional Characteristics of the Landscape. The characteristics of the landscape, by the climate, geographical constraints and different regions have different plants and this plant area landscape determines the local characteristics of the landscape. Heilongjiang ethnic minorities used by the garden plants are obvious of the region, and its life is closely related to the region living in the same area of the nation, in the application of plants both its unity, but also diversity. Therefore, the performance of ethnic minorities in the garden characteristics, the application of regional characteristics of plants and different ethnic groups of plants with each other is complementary.

The Backbone of Evergreen Trees. Minority villages near the gods of the tree and the village in some of the specific location of the village, with evergreen trees, such as various banyan trees, pine, bamboo, etc., these rich cultural connotation of the trees is both national gardens in the indispensable backbone tree species, but also the first choice of tree trees.

The Widespread Use of Edible Plants. Minority villages around the house and the house before the house, the general species with a variety of edible plants, including fruit, food, rice, sorghum, taro, vegetables, cowpea, pepper, etc. These are full of rich ethnic minority life and cultural atmosphere of the plant is the basic material of garden plant configuration.

\section{The Development and Utilization of Minority Garden Plant Culture}

Combined with Landscape Design and Tourism Resources Development. Garden is the crystallization of human culture and there are different cultural background and the formation of different local characteristics of the garden. Many ethnic minorities attach great importance to the front of the house, the village side of the village landscaping, residential buildings before and after the natural planted up to a dozen species, which kind of landscape effect in the garden can reflect a quiet, deep atmosphere.

The gods around the villages, the gods, although the solitary stand in the wilderness, but it is the focus of sight, the main scene of the wilderness, the landscape effect and the garden of the lonely, planted, planted trees. Nature plants and religious plants, folk plants, etc., and the village of buildings contrast set in the garden can be used as a coordinated arrangement of architecture and plants, the performance of national style, regional characteristics of reference at the same time, rich and colorful plants have a deep cultural deposition, each use has history, each plant has a story, before the tree planting, clothes embroidery, sunset, smoke curl, this simple, quiet mountain scenery, is the valuable resource of the Heilongjiang tour, worthy of development and utilization.

Combined with Eco-Environmental Protection and Biodiversity Conservation. The worship of the village and the favorite plants, regardless of individual or forest, due to the constraints of faith, to be preserved to varying degrees, or forbidden to cut down, love to add, such as divine plants, religious plants, etc., or because of customs need although pruning, but no devastation cut, so that a relatively small range of ecological environment from destruction, with local characteristics of native plants, animals, birds, microbes, etc. to protect, also protect the biological diversity. Although biodiversity is the property of natural systems, and in fact it is the product of the interaction between social systems and natural systems, which are the material basis for human 
survival and the use of biodiversity by ethnic minorities while at the same time continuing to recognize and develop biodiversity, which has created a role in the formation and development of biodiversity, which makes the interdependence between biodiversity and national traditional culture. In the long history of the process of common development, so that the national plant culture has become one of the social factors affecting the local biodiversity.

\section{Conclusion}

Heilongjiang ethnic minorities living in this piece of black fertile soil in Heilongjiang, accompanied by green plants, they have used plants to create a unique and diverse plant culture and it has been Chinese splendid cultural treasures in a shiny pearl. With the development of society, the range of communication between the various ethnic groups is expanding, so that the characteristics of the nation's culture are confronted with assimilation, loss of risk. Therefore, taking in-depth study on landscape design, tourism resources development, ecological environment protection and biodiversity conservation has important practical significance.

\section{Acknowledgements}

Fund Project: 1. Supported by Program for the Top Young Innovative Talents of Heihe University (No.2014201-10) supported by Heihe University. 2. Study on Minority Plants with Traditional Knowledge and Plant Resources (KJY201603), supported by Science and Technology Project of Heihe University.

\section{References}

[1] Ivan Marusic.Some observations regarding the education of landscapearchitects for the 21st century [J].Landscape and Urban Planning,2002 (60):95-103.

[2] Xue Jianhua Zhuo Lihuan, Heilongjiang Province, the main urban greening tree species application research [J]. Harbin Normal University, Natural Science Journal 2005, 3: 99-102.

[3] Yang Xiaoxi, on the trend and shortcomings of urban garden design [J]. Forestry Science and Technology Information 2008, 3: 112

[4] See Yan Nailing, Lu Heng, Yu Xiaosheng, et al. New developments in the research of the world's protected areas [J]. Rural Ecological Environment, 2003 (3): 49- 52.

[5] Pei Shengji. The two conventions express a consensus: biodiversity and cultural diversity are interrelated --- Pei Shengji talk about the two diversities[J]. Human and Biosphere, 2007 (5): 23 25. 